\title{
Filamentous fungi as a source of natural antioxidants
}

\author{
Helen Smith $^{\mathrm{a}, *}$, Sean Doyle ${ }^{\mathrm{b}}$, Richard Murphy ${ }^{\mathrm{a}}$ \\ ${ }^{a}$ Alltech, Summerhill Road, Dunboyne, Co. Meath, Ireland \\ ${ }^{\mathrm{b}}$ Maynooth University, Maynooth, Co. Kildare, Ireland
}

\section{A R T I C L E I N F O}

\section{Article history:}

Received 21 November 2014

Received in revised form 4 March 2015

Accepted 25 March 2015

Available online 3 April 2015

\section{Keywords:}

Filamentous fungi

Antioxidant activity

$\beta$-carotene bleaching

Reducing power

CUPRAC

Chelating

Scavenging

Extraction

Antioxidant Components

Phenolic

\begin{abstract}
A B S T R A C T
Ten species of filamentous fungi grown in submerged flask cultures were investigated for antioxidant capacity. Effective antioxidant activity was demonstrated in terms of $\beta$-carotene/linoleic acid bleaching, radical scavenging, reduction of metal ions and chelating abilities against ferrous ions. Different extraction methods affected antioxidant activities through their effect on biologically active compounds produced in fungal mycelia. The methanolic extract of each fungus was typically more effective in antioxidant properties. Phenolic content was established in the range of $0.44-9.33 \mathrm{mg} / \mathrm{g}$, flavonoid contents were in the range of $0.02-3.90 \mathrm{mg} / \mathrm{g}$ and condensed tannin contents were in the range of $1.77-18.83 \mathrm{mg} / \mathrm{g}$. Total phenol content of each extract was attributed to overall antioxidant capacity $(r \geqslant 0.883-1.000)$. Submerged cultivation of Grifola frondosa, Monascus purpureus, Pleurotus spp., Lentinula edodes and Trametes versicolor proved to be an effective method for the production of natural antioxidants.
\end{abstract}

두 2015 Elsevier Ltd. All rights reserved.

\section{Introduction}

For thousands of years fungi have been recognised as nutritious, highly palatable functional foods in many societies and are now accepted as a valuable source for the development of medicines and nutraceuticals (Chang \& Buswell, 1996; Wasser, 2002). Pharmacological and medicinal studies of fungi have shown that the Basidiomycete and Ascomycete divisions are an immense source of biologically active components, yet less than ten percent of all species have been described and even less have been tested for therapeutic significance (Blackwell, 2011; Lindequist, Niedermeyer, \& Julich, 2005). Extensive epidemiology studies have demonstrated a variety of natural foods to be sources of multiple antioxidants which are strongly associated with reduced disease risk (Ferreira, Barros, \& Abreu, 2009; Liu, 2004).

In the present study, nine Basidiomycetes from the genera; Grifola, Pleurotus, Lentinula and Trametes, in addition to one Ascomycete from the genera Monascus were cultivated in submerged flask cultures. Grifola frondosa, Lentinula edodes, Pleurotus ostreatus, Monascus purpureus, Pleurotus citrinopileatus, Pleurotus eryngii, Pleurotus salmoneo-stramineus and Trametes versicolor species were investigated based on the lack of information on

\footnotetext{
* Corresponding author. Tel.: +353 1825 2244; fax: +3531 8252245 .

E-mail address: hsmith@alltech.com (H. Smith).
}

antioxidant compound production in submerged liquid and the potential of each strain from a natural product perspective (Asatiani, Elisashvili, Songulashvili, Reznick, \& Wasser, 2010; Elisashvili, 2012).

The Basidiomycetes chosen in this study have long been recognised as edible or therapeutic fungi (Chang, 1996). For years, research has focused on the antioxidant activity of the fungal fruiting body, as this stage of fungal growth is widely accepted as a nutritional food source. With current research demonstrating that extracts of fungi possess important biological activities, there is increasing interest in the antioxidant potential of fungi at various stages of their development. In addition, there has been little research focused on antioxidant production by submerged cultures of medicinal fungi. Accordingly, the objective of this study was to evaluate the antioxidant properties from the mycelia of several species of filamentous fungi. This incorporated analysis of total antioxidant capacity in terms of $\beta$-carotene bleaching activity, reducing power, CUPRAC, radical scavenging ability and chelating effects on ferrous ions.

Polyphenolic compounds of higher fungi have been demonstrated in vitro to protect against oxidative damage by inhibiting or quenching free radicals and reactive oxygen species. Molecules, such as simple phenolic acids, phenylpropanoids and flavonoids, as well as the highly polymerised molecules; lignin, melanin and tannins, accumulate naturally as end products from 
the shikimate and acetate pathways, with flavonoids representing the most common and widely distributed sub-group with antioxidant activity (Bravo, 1998; Ferreira et al., 2009; Liu, 2004). There are over 8000 naturally occurring phenolic compounds currently known (Balasundram, Sundram, \& Samman, 2006). In this study, the antioxidant production of the main bioactive antioxidant components in the crude mycelial, hot water and methanolic extracts were determined. The data obtained from the present investigation provides a comprehensive description of the antioxidant capacity of each of the selected fungi following growth in submerged culture.

\section{Material and methods}

\subsection{Materials and preparation of extracts}

Nine Basidiomycetes from the genera; Grifola, Pleurotus, Lentinula and Trametes, in addition to one Ascomycota from the genera Monascus, were chosen for investigation. G. frondosa, P. ostreatus (OYRM1) and L. edodes were maintained by Alltech (Bioscience Centre, Dunboyne, Co. Meath, Ireland). P. ostreatus 32783 was supplied by ATCC (American Type Culture Collection, VA, USA). M. purpureus 1604, P. ostreatus 1833, P. citrinopileatus 5341, Pleurotus eryngii 9619, Pleurotus salmoneo-stramineus 5338 and T. versicolor 3086 were supplied by DSMZ GmbH (Braunschweig, Germany). Fungal mycelium was grown by submerged liquid fermentation (SLF) in $500 \mathrm{ml}$ Erlenmeyer flasks. Mycelial biomass was collected and freeze-dried using an Alpha 1-4 LD plus freeze drying unit (Sigma, Osterode am Harz, Germany). A fine powder was collected (1.0 mm (No. 10) mesh) and the dried extract (crude extract) was further extracted using hot water or methanol extraction processes for comparison of antioxidant activity.

Hot water extraction was performed on a Sineo MD-S10 microwave digester (Elementec Ltd., Summerhill, Co. Meath, Ireland). Dry mycelial biomass $(0.5 \mathrm{~g})$ was accurately weighed into the digester cylinders. After the addition of $10 \mathrm{ml}$ deionised water, the mixture was heated at $100{ }^{\circ} \mathrm{C}$ for $20 \mathrm{~min}$ under reflux and allowed to cool for $20 \mathrm{~min}$. After this time, the filtrate was separated from the mycelial biomass by vacuum filtering using No. $42(\times 2)$ Whatman filter paper. The process was repeated twice. The combined filtrate was then freeze-dried and the dry weight recorded. For the methanol extract, freeze-dried mycelial biomass $(5 \mathrm{~g})$ was accurately weighed into a $100 \mathrm{ml}$ sterilin and shaken overnight (18-24 h) with $50 \mathrm{ml}$ of methanol at room temperature. The extract was then filtered through Whatman paper No. $1(\times 2)$ by vacuum filtration. The residue was then resuspended in another $50 \mathrm{ml}$ of methanol. The process was repeated twice. The combined methanol filtrate was transferred to a pre-weighted sterilin and the solvent was evaporated by applying a constant flow of nitrogen. Residual methanol was removed by vacuum pressure at $50{ }^{\circ} \mathrm{C}$ overnight in an oven and the dry weight recorded. Both dried extracts were used directly for analysis of antioxidant components or redissolved in deionised water or methanol, respectively to a concentration of $100 \mathrm{mg} / \mathrm{ml}$ and then diluted to $50,20,10,5,1$, 0.1 and $0.01 \mathrm{mg} / \mathrm{ml}$ for further uses.

\subsection{Total antioxidant activity determination by $\beta$-carotene bleaching assay}

Evaluation of antioxidants was performed using a method developed by Miller (1971). An aliquot (1 ml) of crystallized $\beta$-carotene $(0.2 \mathrm{mg} / \mathrm{ml}$ in chloroform) was dispensed into a round-bottom flask containing $25 \mu$ of purified linoleic acid and $200 \mathrm{mg}$ of TWEEN 20 emulsifier. The chloroform was removed using a Heidolph laborota 4000 rotary evaporator and $50 \mathrm{ml}$ of oxygenated, distilled water (shaken at $500 \mathrm{rpm}$ for $30 \mathrm{~min}$ ) was added to the flask and shaken vigorously. Aliquots $(200 \mu \mathrm{l})$ of each extract $(1 \mathrm{mg} / \mathrm{ml})$ were added to $2.5 \mathrm{ml} \beta$-carotene/linoleic acid emulsion by pipetting into a series of spectrophotometer tubes with caps. A zero reading was taken at $\lambda_{470 \mathrm{~nm}}$ immediately after the addition of the emulsion to the antioxidant solution. Samples were capped and subjected to oxidation by placing in an oven for $3 \mathrm{~h}$ at $50{ }^{\circ} \mathrm{C}$. Antioxidant activity was calculated as follows: $\mathrm{AA} \%=100 \times\left[1-\left(A_{0}-A_{\mathrm{t}} / A_{00}-A_{0 \mathrm{t}}\right)\right]$ where, $A_{0}$ is the absorbance at the beginning of the incubation with the extract, $A_{\mathrm{t}}$ is the absorbance after $3 \mathrm{~h}$ with the extract. $A_{00}=$ is the absorbance at the beginning of the incubation without extract and $A_{0 t}$ is the absorbance after $3 \mathrm{~h}$ without the extract. Samples were read against a blank containing the emulsion minus $\beta$-carotene, i.e. $20 \mathrm{mg}$ linoleic acid with $200 \mathrm{mg}$ TWEEN mixed with $50 \mathrm{ml}$ saturated $\mathrm{H}_{2} \mathrm{O}$ (30 min). BHT and $\alpha$-tocopherol $(1 \mathrm{mg} / \mathrm{ml})$ were tested as comparative positive controls.

\subsection{ABTS $^{+}$radical scavenging activity}

Radical scavenging activity was determined according to the method first reported by Miller, Riceevans, Davies, Gopinathan, and Milner (1993) with slight modifications. ABTS (2,2'-azinobis(3-ethylbenzothiazoline-6-sulphonic acid) was dissolved in water to give a $7 \mathrm{mM}$ concentration stock solution. ABTS radical cation $\left(\mathrm{ABTS}^{+}\right)$was produced by reacting ABTS stock solution with $2.45 \mathrm{mM}$ potassium persulfate $1: 1(\mathrm{v} / \mathrm{v})$ and left in the dark at room temperature for $12-16 \mathrm{~h}$ before use. $\mathrm{ABTS}^{+}$solution was diluted in $95 \%$ ethanol to an absorbance between 0.7 and 0.75 at $\lambda_{734 \mathrm{~nm}}$. The photometric assay was conducted with $180 \mu \mathrm{l}$ of the ABTS reagent and $20 \mu \mathrm{l}$ of the test samples. The optical density was measured at time zero. The radical scavenging activity of the fungal extracts was calculated using the following equation: $\mathrm{E}=\left[\left(A_{\mathrm{o}}-A_{\mathrm{t}}\right) / \mathrm{A}_{\mathrm{o}}\right] \times 100$, where, $A_{0}$ the absorbance of the negative control and $A_{\mathrm{t}}$ is the absorbance of the samples. Radical scavenging activity was expressed as the concentration that scavenged $50 \%$ of the $\mathrm{ABTS}^{+}$radicals $\left(\mathrm{EC}_{50}\right)$. All determinations were carried out in triplicate. Trolox was used as a positive control. The results are normalised and expressed as $\mathrm{EC}_{50}$ values ( $\mathrm{mg}$ extract per $\mathrm{ml}$ ) for comparison. Effectiveness of antioxidant properties is inversely correlated with $\mathrm{EC}_{50}$ value.

\subsection{Ferric reducing antioxidant power (FRAP)}

Reducing power was determined according to the method of Oyaizu (1986), with slight modifications. Fungal extracts $(200 \mu \mathrm{l})$ were mixed with $0.5 \mathrm{ml}$ of $0.2 \mathrm{M}$ phosphate buffer ( $\mathrm{pH} \mathrm{6.6)} \mathrm{and}$ $0.5 \mathrm{ml}$ of $1 \%(\mathrm{w} / \mathrm{v})$ potassium ferricyanide. The reaction mixture was incubated at $50{ }^{\circ} \mathrm{C}$ for $20 \mathrm{~min}$. After the addition of $0.5 \mathrm{ml}$ of $10 \%(\mathrm{w} / \mathrm{v})$ trichloroacetic (TCA), the mixture was centrifuged at $1000 \mathrm{rpm}$ for $10 \mathrm{~min}$ using a Heraeus multifuge (DJB labcare Ltd., Buckinghamshire, UK). An aliquot of supernatant $(0.5 \mathrm{ml})$ was mixed with $0.5 \mathrm{ml}$ of deionised water and $0.1 \mathrm{ml}$ of $0.1 \%(\mathrm{w} / \mathrm{v})$ ferric chloride. Absorbance was measured at $\lambda_{700 \mathrm{~nm}}$ against a blank. Higher absorbance indicated greater reducing power. Tests were carried out in triplicate and the results are expressed as mean values \pm standard deviations. Reducing power was expressed as the concentration $(\mathrm{mg} / \mathrm{ml})$ where the reducing power reached 0.5 $\left(\mathrm{EC}_{50}\right)$. BHT and $\alpha$-tocopherol were used as positive controls and deionised water was used a negative control. The results are normalised and expressed as $\mathrm{EC}_{50}$ values ( $\mathrm{mg}$ extract per $\mathrm{ml}$ ) for comparison. Effectiveness of antioxidant properties is inversely correlated with $\mathrm{EC}_{50}$ value. 


\subsection{Cupric ion reducing antioxidant capacity (CUPRAC)}

Total antioxidant potential using $\mathrm{Cu}$ (II) as an oxidant was assessed using the CUPRAC assay (Apak, Güçlü, \& Özyürek, 2008). To a test tube, $1.5 \mathrm{ml}$ of the test mixture containing $10 \mathrm{mM}$ of copper (II), $7.55 \mathrm{mM}$ neocuproine and $1 \mathrm{M}$ ammonium acetate buffer $(\mathrm{pH} 7.0)$ were added. Following this, $0.5 \mathrm{ml}$ of diluted fungal extracts at various concentrations were added to the reaction tubes to achieve a final volume of $2 \mathrm{ml}$. The tubes were incubated for 30 min at room temperature before the absorbance at $\lambda_{450 \mathrm{~nm}}$ was recorded against a blank. BHT and $\alpha$-tocopherol were used as positive controls.

\subsection{Chelating effects on ferrous ions}

The chelating effect on ferrous ions was determined according to the method of Dinis, Madeira, and Almeida (1994). Each extract $(0.5 \mathrm{ml})$ was mixed with $1.85 \mathrm{ml}$ methanol and $0.05 \mathrm{ml}$ of $2 \mathrm{mM}$ ferrous chloride. The reaction was initiated by the addition of $0.1 \mathrm{ml}$ of $5 \mathrm{mM}$ ferrozine. After $10 \mathrm{~min}$ the absorbance of the mixture was read at $\lambda_{562 \mathrm{~nm}}$ against a blank. A lower absorbance indicated a higher chelating power. Ethylenediaminetetraacetic acid (EDTA) was used as a standard compound. The effective concentration at which $50 \%$ of the ferrous ions were chelated was calculated and obtained by interpolation from linear regression analysis of each extract and EDTA $(0.1-50 \mathrm{mg} / \mathrm{ml})$. The chelating activity was expressed as $\mathrm{EC}_{50}$, the concentration $(\mathrm{mg} / \mathrm{ml})$ that chelated $50 \%$ of the $\mathrm{Fe}^{2+}$ ions. The results are normalised and expressed as $\mathrm{EC}_{50}$ values (mg extract per $\mathrm{ml}$ ) for comparison. Effectiveness of antioxidant properties is inversely correlated with $\mathrm{EC}_{50}$ value.

\subsection{Determination of antioxidant components}

Total phenolic content of the fungal extracts was estimated using the Folin-Ciocalteu reagent method according to Singleton and Rossi with minor modification (Singleton 1985). Sample extracts $(250 \mu \mathrm{l})$ were mixed with $250 \mu \mathrm{l}$ of $10 \%(\mathrm{v} / \mathrm{v})$ FolinCiocalteu reagent, followed by the addition of $500 \mu$ l saturated sodium carbonate $(10 \%, \mathrm{w} / \mathrm{v}$ aqueous solution) after $2 \mathrm{~min}$ of incubation at room temperature. The mixture was placed in the dark for $1 \mathrm{~h}$. Absorbance was then measured at $\lambda_{750 \mathrm{~nm}}$. The concentration of total phenols was calculated based on a calibration curve using gallic acid ranging from 10 to $100 \mu \mathrm{g} / \mathrm{ml}$. The phenol content was expressed as gallic acid equivalent (GAE), which reflects the phenol content as the amount of gallic acid units in $1 \mathrm{~g}$ of extract (mg GAE/g).

Flavonoid content was measured according to the $\mathrm{AlCl}_{3}$ method (Quettier-Deleu et al., 2000). Each extract $(0.5 \mathrm{ml})$ at a concentration of $10 \mathrm{mg} / \mathrm{ml}$ was mixed with $1.0 \mathrm{ml}$ of a $2 \%(\mathrm{v} / \mathrm{v}) \mathrm{AlCl}_{3} \cdot 6 \mathrm{H}_{2} \mathrm{O}$ methanolic solution and the absorbance was measured $10 \mathrm{~min}$ later at $\lambda_{430 \mathrm{~nm}}$. Quantification of flavonoids was calculated on the basis on a calibration curve of quercetin $(0.01-50 \mu \mathrm{g} / \mathrm{ml})$ and is expressed as quercetin equivalent $(\mathrm{QE})$, which reflects the flavonoid content as the amount of quercetin units in $1 \mathrm{~g}$ of extract (mg QE/g).

Total condensed tannin content was determined according to the method of Yim, Fook, See, and Chun (2009). Methanol and aqueous fungal extracts were dissolved in methanol and water, respectively. An aliquot of each extract $(50 \mu \mathrm{l})$ was mixed with $1.5 \mathrm{ml}$ of $4 \%(\mathrm{w} / \mathrm{v})$ vanillin in methanol, followed by the addition of $750 \mu \mathrm{l}$ concentrated $\mathrm{HCl}$. After mixing well, the mixture was allowed to stand at room temperature for $20 \mathrm{~min}$ in darkness. The blank was $4 \%(\mathrm{v} / \mathrm{v})$ concentrated $\mathrm{HCl}$ in methanol. The absorbance was read against a corresponding blank at $\lambda_{500 \mathrm{~nm}} \cdot(+)-$ Catechin was used to prepare the standard curve $(50-1000 \mu \mathrm{g} /$ $\mathrm{ml}$ ) and the results were expressed as catechin equivalent (CE), which reflects the tannin content as the amount of catechin in $1 \mathrm{~g}$ of extract ( $\mathrm{mg} \mathrm{CE} / \mathrm{g}$ ).

\subsection{Statistical analysis}

Statistical analyses of results were performed using Minitab statistical software package version 16 (Coventry, UK). One-way analysis of variance (ANOVA) and Tukey's multiple comparisons were carried out to test any significant differences among means, with a confidence level of $95 \%$. One-way analysis of variance (ANOVA) and Dunnett's comparisons were carried out to test any significant differences between each test mean and a control mean, where the confidence level was set at 95\%. Significant levels were defined using $p \leqslant 0.05$. For the correlations, the Minitab statistical software package version 16 (Coventry, UK) was used to determine the Pearson's correlation coefficient $(r)$ between the content of total phenols, flavonoids and condensed tannin, to the activity (\%) of each antioxidant attribute. $\mathrm{EC}_{50}$ determinations were calculated using GraphPad PRISM, version 6.03 for Windows (GraphPad Software, California, USA). The data was fitted by nonlinear regression to the variable slope dose-response curves, with a confidence interval of $95 \%$. $Y$ was the percent activity and $X$ was the corresponding Log [extract concentration]. The interpolated $\mathrm{EC}_{50}$ parameter is the absolute $\mathrm{EC}_{50}$, and it is defined as the effective concentration giving an inhibition of $50 \%$.

\section{Results and discussion}

\subsection{Extraction yield}

The extraction yield obtained for methanol fractions was considerably lower than the yield recovered for water soluble fractions for all ten selected species (Table 1). The extraction processes employed provided a good source of comparison of antioxidant properties between the crude mycelial extract (intact cell wall) and the microwave-assisted hot water extract (filtrate), where polysaccharides and other metabolites are extracted from the cell. The quantity recovered following hot water extraction (40-58\%) was quite high. The difference between the yields for hot water and methanol extracts is believed to be attributed to the amount of soluble polysaccharides in the water extract. Hot water extraction is the most widely used technique for polysaccharide extraction and is the only clinically validated method to effectively dissolve indigestible fibre (chitin), allowing the fibre to be removed from the extract when the water is removed (Ong, Woo, Yong, \& Binte, 2003). Extraction of polysaccharides from the fungal cell is an important procedure for their application in biological

Table 1

Extraction recovery (\%) from filtrate.

\begin{tabular}{lcl}
\hline \multirow{2}{*}{ Fungi } & \multicolumn{2}{l}{ \% Recovery } \\
\cline { 2 - 3 } & Methanol extract & Hot water extract \\
\hline Grifola frondosa & $30.61 \pm 2.89$ & $58.28 \pm 8.00$ \\
Lentinula edodes & $33.01 \pm 4.88$ & $56.80 \pm 4.42$ \\
Monascus purpureus & $5.97 \pm 2.19$ & $40.30 \pm 6.55$ \\
OYRM1 & $23.57 \pm 3.39$ & $56.76 \pm 8.43$ \\
Pleurotus ostreatus 1833 & $33.93 \pm 2.10$ & $50.55 \pm 3.36$ \\
Pleurotus ostreatus 32783 & $27.49 \pm 8.05$ & $56.23 \pm 3.23$ \\
Pleurotus citrinopileatus & $20.57 \pm 8.20$ & $51.15 \pm 0.53$ \\
Pleurotus eryngii & $33.15 \pm 2.31$ & $54.96 \pm 1.45$ \\
Pleurotus salmoneo-stramineus & $19.81 \pm 6.11$ & $57.72 \pm 9.47$ \\
Trametes versicolor & $30.60 \pm 2.79$ & $42.02 \pm 6.76$ \\
\hline
\end{tabular}

Data represents the mean $\pm \mathrm{SD}(n=3)$ of recovered dry extract following hot water and methanol extraction from crude mycelial biomass $(5 \%, \mathrm{w} / \mathrm{v})$. Abbreviations: OYRM1, Pleurotus ostreatus.

a Total dry weight (\%) recovered following extraction. 
processes. Solvent selection during extraction leads to the extraction of a range of different compounds possibly with varying biological properties (Rajauria, Jaiswal, Abu-Gannam, \& Gupta, 2013). When performing natural compound extraction using polar organic solvents, such as methanol, flavonoids, alkaloids, coumarins, fatty acids and triterpenes are commonly extracted. The recovery (\%) of $M$. purpureus was substantially less than the other species with both extraction processes. This is believed to be associated with the characteristic morphological differences of this species compared to the others.

\subsection{Antioxidant activity}

Using the $\beta$-carotene method of antioxidant determination, the activities of the crude mycelia, hot water and methanol extract were determined in comparison to the reference standards BHT (butylated hydroxytoluene) and $\alpha$-tocopherol. Table 2 shows the ability of the various extracts to inhibit the peroxidation of linoleic acid as the antioxidant activity (\%). With regard to the crude, hot water and methanolic extracts, P. citrinopileatus (84\%), P. 32783 (66\%) and $M$. purpureus (84\%) had the highest antioxidant activity, relative to BHT and $\alpha$-tocopherol, respectively (Table 2). Variation between oxidation ability of the different extracts may be due to possible deviations of phenolic, ascorbic acid and $\beta$-carotene content in response to the aging process of each particular species of fungi. A study by Taylor and Richardson (1980) found that cysteine exhibited better protection of a linoleate emulsion than BHA, BHT and $\alpha$-tocopherol against oxidation by haemoglobin. Lee, Huang, Liang, and Mau (2007a) stated that mycelium of P. citrinopileatus containing $9.11 \mathrm{mg} / \mathrm{g}$ of free cysteine, was steadily soluble in water and consequently was believed to have contributed to the antioxidant activity of cold and hot water extracts. In the present study, most capacity was retained in the crude extract of $G$. frondosa, $L$. edodes, M. purpureus, P. 1833 and P. citrinopileatus. This observation suggests that further extraction of the biomass may be detrimental to $\beta$-carotene bleaching activity of these species. The methanol extraction process was most successful in retaining the overall content of antioxidant compounds across the range of species tested. Methanol extracts from M. purpureus, OYRM1, P. 32783, P. salmoneo-stramineus and T. versicolor resulted in the highest inhibition of linoleic acid oxidation. Altogether, the methanol extracts restricted oxidation by at least $53 \%$. The antioxidant activity of M. purpureus and $P .32783$ were statistically similar $(p \leqslant 0.05)$ to that of $\alpha$-tocopherol at the same concentration (Table 2 ).

Altogether, the observed measure of activity using this method of analysis may be due to the reducing of hydroperoxide, inactivation of free radicals, complexation with metal ions, or a combination thereof (Lee et al., 2007a; Taylor \& Richardson, 1980). Differences in the level of oxidation from the different extraction methods employed are believed to be due to the presence of different quantities of antioxidant molecules isolated, depending on the species. The data revealed evidence that various extracts from the different species of fungi are capable of effectively reducing the extent of $\beta$-carotene destruction by neutralising the linoleate free radical to a high degree.

\subsection{Radical scavenging ability}

The reactivity of the various antioxidants was compared to the reactivity of Trolox, a water-soluble vitamin E analogue. The relative radical scavenging capacity of fungal extracts in terms of their $\mathrm{EC}_{50}$ values are displayed in Table 2 . In agreement with the data obtained following the $\beta$-carotene assay, the extraction process was an extremely important factor in the isolation of antioxidant compounds. The methanol extracts generally demonstrated the greatest activity proceeded by the hot water and crude extracts.
The greater ability of the methanol extract might also be due to more hydrogen donating components extracted by organic solvents (Arnao, 2000; Lee et al., 2007a), in this instance, methanol. Nonetheless, it may be considered that for these selected species (Table 2), both the alcoholic and aqueous extracts gave rise to the presence of significant amounts of antioxidant compounds, as they show the ability to react with $\mathrm{ABTS}^{+}$radicals. The crude extract of $P$. 1833, the hot water extract of $T$. versicolor and the methanolic extract of $M$. purpureus were significantly more effective at scavenging $\mathrm{ABTS}^{+}$radicals than other species, as depicted in Table 2 in bold.

\subsection{Ferric reducing antioxidant power (FRAP)}

The reducing power of fungi is directly associated to the hydrogen donating ability of the antioxidant compounds (Jayakumar, Thomas, \& Geraldine, 2009; Shimada, Fujikawa, Yahara, \& Nakamura, 1992). From the data obtained, it was established that each species of fungi possessed reducing capacity. The results demonstrated considerable differences in reducing power between crude, hot water and methanol extracts for each fungus. Generally, with the exception of $P .1833$, the methanol and hot water extracts demonstrated the strongest reducing power. The reactivity of water soluble antioxidants including phenolics, thiols and vitamin $C$ could have contributed to the variation observed for this species. As FRAP methods assess electron transfer ability directly, $P .1833$ is assumed to have greater hydrogen donating components which are soluble in organic solvents, extracted in the methanol extract, as well as possibly having its hydrogen donating ability reduced following hot water extraction. The hot water extract of T. versicolor had the lowest effective concentration at which the absorbance was 0.5 for reducing power (Table 2), similar to the $\mathrm{ABTS}^{+}$radical scavenging assay, of which the hot water extract of this species had the most scavenging activity of $\mathrm{ABTS}^{+}$radicals (Table 2). These observations confirm a relationship between both methods, which is believed to be attributed to the shared mode of analysis associated with these assays, in that they are based on electron transfer by hydrogen donating compounds. Altogether, each type of extract demonstrated good reducing capacity for each of the fungal species tested. The methanol extraction process positively impacted the reducing power ability compared to the crude mycelial extract by a significant degree $(p \leqslant 0.05)$ for each of the selected fungal species. The crude extract of $P$. 1833, the hot water extract of $T$. versicolor and the methanolic extract of $P .32783$ were significantly more effective reducing agents, as denoted in bold in Table 2. Additionally, the reducing power of the crude, hot water and methanol fungal extracts acted as a function of increasing concentration.

Notably, the fungal extracts showed variable reducing capacity with each extraction process. This is believed to be attributed to the different antioxidant compounds (and concentration of compounds) isolated with either type of extraction (hot water and methanol). That being said, both G. frondosa and L. edodes exhibited relatively low reducing power for each type of extract, suggesting differences may also be a result of species specificity.

It was evident that the reducing power of the fungal extracts demonstrated a dose-related effect. At higher concentrations $(20-50 \mathrm{mg} / \mathrm{ml})$ the reducing power of various extracts was most like the control $\alpha$-tocopherol $(1 \mathrm{mg} / \mathrm{ml})$ for most fungal species, as was demonstrated by a gradual plateau effect at high concentrations. The moderate to high efficiency of the hot water extracts of OYRM1, P. 32783, P. citrinopileatus, P. salmoneo-stramineus and $T$. versicolor $(1-50 \mathrm{mg} / \mathrm{ml})$ is believed to be attributed to the use of the microwave extraction process under controlled conditions. These extraction conditions are assumed to have contributed to extraction efficiency consequently increasing the recovery of 
Table 2

Summary of antioxidant activity (AA) of fungal extracts in relation to total phenolic ${ }^{x}$, flavonoid ${ }^{y}$ and condensed tannin ${ }^{z}$ content. $^{\text {. }}$

\begin{tabular}{|c|c|c|c|c|c|c|c|c|c|c|c|}
\hline $\begin{array}{l}\text { Antioxidant } \\
\text { activity }\end{array}$ & $\begin{array}{l}\text { Grifola } \\
\text { frondosa }\end{array}$ & $\begin{array}{l}\text { Lentinula } \\
\text { edodes }\end{array}$ & $\begin{array}{l}\text { Monascus } \\
\text { purpureus }\end{array}$ & OYRM1 & $\begin{array}{l}\text { Pleurotus } \\
1833\end{array}$ & $\begin{array}{l}\text { Pleurotus } \\
32783\end{array}$ & $\begin{array}{l}\text { Pleurotus } \\
\text { scitrinopileatus }\end{array}$ & $\begin{array}{l}\text { Pleurotus } \\
\text { eryngii }\end{array}$ & $\begin{array}{l}\text { Pleurotus } \\
\text { salmoneo-str. }\end{array}$ & $\begin{array}{l}\text { Trametes } \\
\text { versicolor }\end{array}$ & Control $^{d}$ \\
\hline \multicolumn{12}{|l|}{ Crude extract } \\
\hline $\begin{array}{l}\beta \text {-carotene (\%) } \\
\text { CUPRAC }\end{array}$ & $\begin{array}{r}84.09 \pm 1.15 \\
0.41 \pm 0.12\end{array}$ & $\begin{array}{r}80.17 \pm 0.95 \\
0.25 \pm 0.03\end{array}$ & $\begin{array}{r}80.45 \pm 1.37 \\
1.15 \pm 0.08\end{array}$ & $\begin{array}{r}24.21 \pm 0.60 \\
0.68 \pm 0.00\end{array}$ & $\begin{array}{r}71.33 \pm 1.72 \\
0.80 \pm 0.06\end{array}$ & $\begin{array}{r}48.93 \pm 0.44 \\
0.91 \pm 0.02\end{array}$ & $\begin{array}{r}\mathbf{8 4 . 4 0} \pm \mathbf{0 . 7 8} \\
0.87+0.03\end{array}$ & $\begin{array}{r}38.57 \pm 0.06 \\
120+0.03\end{array}$ & $\begin{array}{r}22.13 \pm 0.08 \\
0.98+0.04\end{array}$ & $35.59 \pm 0.05$ & $\begin{array}{r}96.47 \pm 1.30^{++} \\
244+0.02^{++}\end{array}$ \\
\hline $\begin{array}{l}\text { CUPRAC } \\
\text { ABTS activity }\end{array}$ & $25.95 \pm 0.03^{\mathrm{x}}$ & $33.18 \pm 0.16^{\mathrm{xz}}$ & $\begin{array}{c}1.15 \pm 0.08 \\
19.79 \pm 0.13^{\mathrm{xz}}\end{array}$ & $\begin{array}{c}0.68 \pm 0.00 \\
12.23 \pm 0.06^{\mathrm{xz}}\end{array}$ & $\begin{array}{r}0.80 \pm 0.06 \\
\mathbf{1 0 . 1 6} \pm \mathbf{0 . 0 6}^{\mathrm{xz}}\end{array}$ & $\begin{array}{c}0.91 \pm 0.02 \\
15.12 \pm 0.02^{\mathrm{xyz}}\end{array}$ & $\begin{array}{c}0.87 \pm 0.03 \\
13.04 \pm 0.05^{\mathrm{xz}}\end{array}$ & $\begin{array}{c}1.20 \pm 0.03 \\
13.07 \pm 0.03^{x z}\end{array}$ & $\begin{array}{c}0.98 \pm 0.04 \\
23.90 \pm 0.09^{x}\end{array}$ & $\begin{array}{c}0.56 \pm 0.02 \\
24.51 \pm 0.03^{x}\end{array}$ & $\begin{array}{l}2.44 \pm 0.02 \\
0.02 \pm 0.04^{+}\end{array}$ \\
\hline & & & & & & & & & & & $0.02 \pm 0.04$ \\
\hline $\begin{array}{l}\text { Reducing } \\
\text { Power }^{\mathrm{b}}\end{array}$ & $37.78 \pm 0.01^{x}$ & $47.51 \pm 0.11^{\mathrm{x}}$ & $24.83 \pm 0.21^{\mathrm{xyz}}$ & $13.96 \pm 0.08^{x}$ & $6.78 \pm 0.05^{x y z}$ & $21.93 \pm 0.18$ & $18.77 \pm 0.06^{\mathrm{y}}$ & $8.53 \pm 0.06^{\mathrm{yz}}$ & $14.07 \pm 0.04^{y z}$ & $43.30 \pm 0.01^{x}$ & $0.56 \pm 0.03^{++}$ \\
\hline $\begin{array}{l}\text { Chelating } \\
\text { ability }^{c}\end{array}$ & $4.57 \pm 0.09$ & $3.65 \pm 0.13^{x}$ & $1.22 \pm 0.45$ & $1.13 \pm 0.23$ & $1.16 \pm 0.26$ & $1.12 \pm 0.29$ & $1.27 \pm 0.30$ & $1.39 \pm 0.29$ & $1.39 \pm 0.16$ & $1.34 \pm 0.18$ & $0.07 \pm 0.02^{+++}$ \\
\hline \multicolumn{12}{|c|}{ Hot water extract } \\
\hline$\beta$-carotene & $34.83 \pm 1.57$ & $22.07 \pm 1.31$ & $60.13 \pm 3.12$ & $63.37 \pm 2.67$ & $50.82 \pm 3.74$ & $65.98 \pm 2.08$ & $56.80 \pm 1.59$ & $62.65 \pm 1.73$ & $57.73 \pm 2.01$ & $59.71 \pm 3.55$ & $94.69 \pm 3.57^{++}$ \\
\hline CUPRAC & $1.59 \pm 0.05$ & $1.74 \pm 0.06$ & $2.06 \pm 0.02$ & $0.93 \pm 0.01$ & $2.33 \pm 0.00^{*}$ & $1.22 \pm 0.02$ & $1.53 \pm 0.01$ & $1.75 \pm 0.01$ & $2.19 \pm 0.00$ & $2.08 \pm 0.03$ & $2.43 \pm 0.02^{++}$ \\
\hline ABTS activity ${ }^{\mathrm{a}}$ & $14.79 \pm 0.04^{\mathrm{x}}$ & $13.77 \pm 0.04$ & $4.63 \pm 0.12^{x y}$ & $7.67 \pm 0.07^{x y}$ & $7.38 \pm 0.03^{\mathrm{xy}}$ & $3.95 \pm 0.04^{x}$ & $6.21 \pm 0.07^{\mathrm{xy}}$ & $5.36 \pm 0.05^{x}$ & $7.67 \pm 0.07^{x}$ & $2.34 \pm 0.06^{x}$ & $0.02 \pm 0.04^{+}$ \\
\hline $\begin{array}{l}\text { Reducing } \\
\text { Power }^{\mathrm{b}}\end{array}$ & $15.11 \pm 0.09^{\mathrm{xz}}$ & $13.20 \pm 0.08^{\mathrm{xz}}$ & $10.80 \pm 0.06^{\mathrm{xyz}}$ & $5.43 \pm 0.05^{\mathrm{yz}}$ & $7.51 \pm 0.14^{x y z}$ & $4.61 \pm 0.04^{x z}$ & $5.99 \pm 0.07^{\mathrm{yz}}$ & $6.70 \pm 0.04^{\mathrm{xyz}}$ & $5.71 \pm 0.11^{\mathrm{yz}}$ & $3.56 \pm 0.05^{x z}$ & $0.56 \pm 0.03^{++}$ \\
\hline $\begin{array}{l}\text { Chelating } \\
\text { ability }^{\mathrm{c}}\end{array}$ & $0.64 \pm 0.07^{x z}$ & $0.70 \pm 0.09$ & $0.66 \pm 0.17^{\mathrm{xy}}$ & $1.47 \pm 0.27^{y}$ & $0.72 \pm 0.10$ & $0.87 \pm 0.08$ & $1.11 \pm 0.18^{x y}$ & $2.60 \pm 0.19$ & $0.81 \pm 0.17^{x z}$ & $0.79 \pm 0.17$ & $0.07 \pm 0.02^{+++}$ \\
\hline \multicolumn{12}{|l|}{ Methanol extract } \\
\hline$\beta$-carotene & $65.22 \pm 1.80$ & $76.61 \pm 1.06$ & $83.94 \pm 0.70^{*}$ & $77.41 \pm 0.75$ & $63.49 \pm 1.64$ & $83.13 \pm 0.84^{*}$ & $53.60 \pm 2.88$ & $53.72 \pm 0.05$ & $59.73 \pm 0.70$ & $63.94 \pm 0.05$ & $93.93 \pm 1.10^{++}$ \\
\hline CUPRAC & $2.34 \pm 0.05^{*}$ & $2.29 \pm 0.10$ & $2.20 \pm 0.03$ & $1.85 \pm 0.01$ & $2.12 \pm 0.05$ & $2.30 \pm 0.00^{*}$ & $2.00 \pm 0.05$ & $2.24 \pm 0.02$ & $2.25 \pm 0.05$ & $2.34 \pm \mathbf{0 . 0 9}^{*}$ & $2.41 \pm 0.02^{++}$ \\
\hline ABTS activity $^{\mathrm{a}}$ & $8.43 \pm 0.04^{\mathrm{xyz}}$ & $9.90 \pm 0.03^{x y z}$ & $1.84 \pm 0.05^{x z}$ & $3.41 \pm 0.07^{\mathrm{xyz}}$ & $8.90 \pm 0.04^{\mathrm{xyz}}$ & $2.72 \pm 0.08^{x}$ & $2.62 \pm 0.06^{x}$ & $6.25 \pm 0.04^{\mathrm{xyz}}$ & $7.71 \pm 0.03^{\mathrm{xyz}}$ & $8.22 \pm 0.03^{x y z}$ & $0.02 \pm 0.04^{+}$ \\
\hline $\begin{array}{l}\text { Reducing } \\
\text { power }^{\mathrm{b}}\end{array}$ & $5.01 \pm 0.15^{x y z}$ & $7.08 \pm 0.14^{\mathrm{xyz}}$ & $4.22 \pm 0.08^{x y z}$ & $2.96 \pm 0.07$ & $2.93 \pm 0.07^{z}$ & $2.44 \pm 0.04$ & $2.88 \pm 0.02^{z}$ & $4.06 \pm 0.07^{x y z}$ & $2.97 \pm 0.02$ & $3.42 \pm 0.14^{\mathrm{xy}}$ & $0.56 \pm 0.03^{++}$ \\
\hline $\begin{array}{l}\text { Chelating } \\
\text { ability }\end{array}$ & $4.09 \pm 0.12$ & $4.24 \pm 0.11$ & $4.67 \pm 0.07$ & $7.60 \pm 0.04$ & $5.84 \pm 0.07^{z}$ & $6.18 \pm 0.05^{x}$ & $4.31 \pm 0.12^{x}$ & $6.20 \pm 0.05$ & $9.56 \pm 0.06^{x z}$ & $4.84 \pm 0.07^{z}$ & $0.07 \pm 0.02^{+++}$ \\
\hline
\end{tabular}

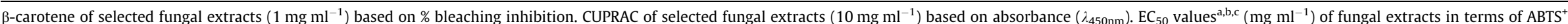

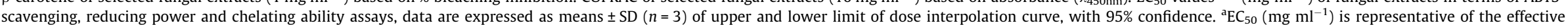

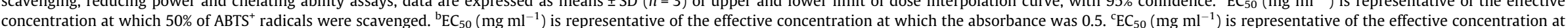

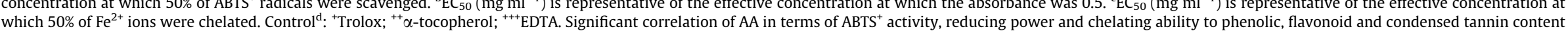

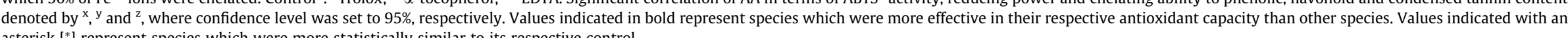
asterisk $\left.{ }^{*}\right]$ represent species which were more statistically similar to its respective control.

Abbreviations: Pl., Pleurotus; OYRM1, Pleurotus ostreatus; Peurotus salmoneo-str., Pleurotus salmoneo-stramineus. 
biologically active compounds compared to other investigations. At $1 \mathrm{mg} / \mathrm{ml}$ the mycelial hot water extract of $P$. eryngii grown by SLF demonstrated a reducing power of $0.06 \pm 0.00$. Abdullah, Ismail, Aminudin, Shuib, and Fye (2012) demonstrated a hot water extract of $P$. eryngii at $1 \mathrm{mg} / \mathrm{ml}$ to be $0.17 \pm 0.04$, however, this study was based on the fungal fruiting body. This highlights that there is considerable differences in effectiveness of biologically active compounds at various stages of growth.

At $50 \mathrm{mg} / \mathrm{ml}$, the crude extract of $P .1833$, the hot water extract of $T$. versicolor and the methanol extract of $P .32783$ had the strongest reducing capacity of each extraction process, as they reached a plateau at this concentration. This may be attributed to the aqueous extracts having a higher polyphenol content and the methanol extract having a higher content of reductones, such as ascorbic acid, which react with free radicals to stabilise and block radical chain reactions (Ferreira, Baptista, Vilas-Boas, \& Barros, 2007; Vamanu, 2012).

Overall, it was evident that the antioxidants produced from the various Pleurotus spp., G. frondosa, M. purpureus and T. versicolor were potent reducing agents with increasing concentration. That being said, the use of ferric ions to monitor antioxidant activity can lead to an underestimation of the antioxidant potential as some antioxidants, such as thiols, are not detected using this method. As such, the FRAP method is recommended for use in conjunction with other methods (Prior, Wu, \& Schaich, 2005). Although the data demonstrates the presence of these antioxidants using the FRAP assay, it does not provide information on whether the antioxidants measured have any biological role. In addition, antioxidants detected by FRAP are limited to water soluble compounds (Apak et al., 2007; Pulido, Bravo, \& Saura-Calixto, 2000). Considering the methanol extract contained the most active FRAP, the data suggests that a high quantity of antioxidants with electron transfer ability or hydrogen donating components, which are soluble in organic solvents are present in this extract.

\subsection{Cupric ion reducing antioxidant capacity (CUPRAC)}

Absorbance values for fungal extracts and reference standards were measured at a concentration of $10 \mathrm{mg} / \mathrm{ml}$ for direct comparison of CUPRAC activity. At $10 \mathrm{mg} / \mathrm{ml}$ the methanol extract showed the highest CUPRAC compared to the other extracts for the majority of filamentous fungal species. As illustrated in Table 2, the hot water extract of $P .1833$ had higher CUPRAC $(2.33 \pm 0.00)$ than the methanol extract $(2.12 \pm 0.05)$. Although both extracts of this species demonstrated good antioxidant activity, the hot water extract had a slightly higher capacity to reduce cupric ions compared to the methanol extract. The crude extract of this species demonstrated the strongest reducing power and scavenging activity compared to the other species (Table 2). Altogether, the CUPRAC $(10 \mathrm{mg} / \mathrm{ml})$ of the methanol extracts ranged from $1.85 \pm 0.01$ (OYRM1) to $2.34 \pm 0.05$ (G. frondosa), $0.93 \pm 0.01$ (OYRM1) to $2.33 \pm 0.00(P .1833)$ for the hot water extracts and $0.25 \pm 0.03$ ( $L$. edodes) to $1.20 \pm 0.03$ (P. eryngii) for the crude extracts. Methanol extracts of $G$. frondosa, $P .32783$ and $T$. versicolor $(10 \mathrm{mg} / \mathrm{ml})$ were significantly similar $(p \leqslant 0.05)$ to $\alpha$-tocopherol $(1 \mathrm{mg} / \mathrm{ml})$ (Table 2). Also, methanol extracts of $G$. frondosa, L. edodes, $P$. 32783 and $T$. versicolor were equivalent $(p \leqslant 0.05)$ to BHT $(2.40 \pm 0.00)$. The CUPRAC of each fungal extract was dependant on the species and extraction process. At $10 \mathrm{mg} / \mathrm{ml}$ the hot water and methanol extracts produced CUPRAC comparable to the positive antioxidant controls. The hot water extract of $P .1833$ was equivalent to BHT $(p \leqslant 0.05)$, as was the methanol extract of $L$. edodes. In addition, the methanol extracts of $G$. frondosa, $P$. 32783 and $T$. versicolor $(10 \mathrm{mg} / \mathrm{ml})$ were significantly similar $(p \leqslant 0.05)$ to $\alpha$-tocopherol and BHT $(1 \mathrm{mg} / \mathrm{ml})$, which is noteworthy.
There are a number of advantages of this method for the determination of antioxidant capacity. There is no risk of overestimation (under basic conditions) or underestimation (under acidic conditions) of total antioxidant capacity as the optimal $\mathrm{pH}$ of this method is close to the physiological pH (Apak et al., 2007). Similar to other electron transfer assays, the antioxidant capacity is assumed to be equal to the reducing capacity of the extracts (Huang, Ou, \& Prior, 2005). This method may be classed as advantageous over FRAP since the redox chemistry of copper (II) should have faster kinetics (Apak et al., 2007). Also, the CUPRAC method is capable of assaying both hydrophilic and lipophilic antioxidants, as the bis(neocuproine)copper (I) cation chromophore is soluble both in water and organic media (Apak et al., 2007).

Overall, with exception of the hot water extract of $P$. 1833, the data revealed that the methanol extract had the highest CUPRAC in each filamentous fungal species tested. The utilisation of CUPRAC in this investigation contributed to the evaluation of antioxidant potential of these species. This is the first report on the evaluation of antioxidant activity of the mycelium of these fungi, using these extraction techniques tested by the CUPRAC method. The methanol extract of $P .32783(10 \mathrm{mg} / \mathrm{ml})$ which was statistically similar $(p \leqslant 0.05)$ to both $\alpha$-tocopherol (Table 2$)$ and BHT $(1 \mathrm{mg} / \mathrm{ml})$ also had the lowest $\mathrm{EC}_{50}$ value $(p \leqslant 0.05)$ for FRAP (Table 2). Additionally, the FRAP of the crude extract of $P$. 1833, demonstrated the lowest $\mathrm{EC}_{50}$ value. The hot water extract of this species demonstrated the best CUPRAC compared to the other fungi and was statistically similar $(p \leqslant 0.05)$ to $\alpha$-tocopherol. This association between different methods of analysis suggests that antioxidant capacity was a not a response to flavonoids or an SH bearing antioxidant and was most likely due to electron transfer ability. With consideration of both ABTS and CUPRAC methods, which measure both hydrophilic and lipophilic antioxidant capacities, the crude and hot water extract of $P .1833$ was the most effective species compared to the others. The relationship with antioxidant capacity is most likely due to radical scavenging ability via electron transfer.

\subsection{Chelating effects on ferrous ions}

The ability of the extracts to inhibit the complex formation of ferrozine with ferrous ions is displayed in Table 2. The chelating activity at various concentrations of the different fungal extracts was examined and compared to a chelating standard, EDTA. The data shows that the chelating ability of extracts was moderate to high. A significant difference $(p \leqslant 0.05)$ in the presence of chelating antioxidants following extraction was observed for some species. According to their $\mathrm{EC}_{50}$ value $(\mathrm{mg} / \mathrm{ml})$, the crude extract of $P$. 32783 , as well as the hot water and methanol extract of $G$. frondosa had the most chelating power of the species analysed (Table 2).

The fungal extracts and reference standard EDTA demonstrated interference with the formation of ferrous and ferrozine complex. Interestingly, the water extracts (mostly microwave assisted hot water extracts) showed the highest ferrous iron chelating activity, preceded by the methanol extracts, which exhibited a weaker chelating effect for each fungal species, suggesting higher solubility and chelation of the metal ions in aqueous solution. That being said, both the methanol and water extracts demonstrated iron binding capacity, suggesting that total antioxidant activity was related to the capacity to chelate metal ions. As the metal chelating activity increased with increasing concentrations, fungal extracts demonstrated effective chelating activity and captured ferrous ion before ferrozine.

At $10 \mathrm{mg} / \mathrm{ml}$ the chelating effect of crude fungal extracts ranged from $86(P .32783)$ to $97 \%$ ( $P$. salmoneo-stramineus), hot water extracts ranged from 74 ( $P$. citrinopileatus) to $95 \%$ ( $G$. frondosa) 
and methanol extract ranged from 52 ( $P$. salmoneo-stramineus) to $85 \%$ ( $P$. eryngii). EDTA showed an excellent chelating ability of $99 \%$ at a concentration as low as $1 \mathrm{mg} / \mathrm{ml}$.

This investigation demonstrated that fungal mycelial biomass as a crude extract or following various extraction processes can effectively slow the rate of oxidation by chelation of pro-oxidant metals. As ferrous ions are the most effective pro-oxidants in food systems, the high ferrous-ion chelating abilities of the various extracts from the mycelium of each of the species tested would be beneficial if formulated into foods (Mau, Chang, Huang, \& Chen, 2004). It was observed that the hot water extract of G. frondosa, L. edodes, M. purpureus, P. 1833, P. 32783, P. citrinopileatus, $P$. salmoneo-stramineus and $T$. versicolor attributed to a greater chelating effect compared to the crude mycelia and methanol extracts, thereby; this method of extraction allowed the isolation of compounds responsible for chelation of metal ions more effectively. On the contrary, the crude extract of OYRM1 and P. eryngii had the highest chelating effect, indicative of the water extracts more effectively isolating compounds responsible for slowing the progression of oxidation caused by metal ions. It is possible that the high activity associated with the fungal antioxidants is a consequence of a high manifestation of phenolic compounds in the extracted fungal mycelia. Phenolic compounds can act as antioxidants in many ways and in relevant literature, have been found to chelate to metal ions, prevent radical formation and improve the antioxidant endogenous system (Al-Azzawie \& Alhamdani, 2006). This is significant as metal ions are proposed as the catalysts for the initial formation of reactive oxygen species.

\subsection{Antioxidant components}

Naturally occurring antioxidant components, including phenols, flavonoids and condensed tannins were found in the hot water and methanol extracts from $P$. ostreatus, $P$. citrinopileatus, $P$. eryngii, $P$. salmoneo-stramineus, G. frondosa, $T$. versicolor, $M$. purpureus and $L$. edodes. Table 3 summarises the effect of extraction on antioxidant component isolation and provides an overview of the antioxidant contribution of each selected fungal species.

A significantly higher content of phenols was obtained following some form of extraction from G. frondosa, L. edodes, M. purpureus, OYRM1, P. 32783, P. citrinopileatus and T. versicolor compared to the crude mycelium. A higher yield of total phenols is usually obtained using water or solvents of high polarity during extraction, such as methanol and ethanol (Yim et al., 2009). A higher yield of phenolic compounds were retained following methanol extraction for $M$. purpureus, OYRM1, P. 32783, P. citrinopileatus, $P$. eryngii, $P$. salmoneo-stramineus and T. versicolor. Apart from $P$. 32783, a significantly higher content $(p \leqslant 0.05)$ of condensed tannin was retained in the hot water extract of each species examined. Apart from the methanol extract of OYRM1, both extraction processes tested (methanol and hot water) significantly influenced the total flavonoid content of each species of fungi $(p \leqslant 0.05)$. Therefore, the extraction methods tested had a significant positive impact on the extraction of flavonoids. The flavonoids isolated were mostly water-soluble compounds, as the highest content was observed in hot water extracts. Thereby, microwave assisted extraction permitted improvement of extraction of bioactive compounds in combination with an accelerated extraction process.

It is recognised that further developmental stages of fungal growth can contain more antioxidative compounds than the mycelium; however, growth by submerged liquid fermentation represents a fast, industrial suitable method of cultivation for the production of antioxidant compounds. Table 3 demonstrates that extraction conditions can significantly improve efficiency in order to obtain high yields of particular antioxidant compounds. A similar quantity of phenols was obtained from the mycelium of G. frondosa (2.31 mg GAE/g) when compared to a study by Mau et al. (2004), which measured the phenolic content of the mycelium of this species $(1.59 \mathrm{mg} / \mathrm{g}$ ) using the Folin-Ciocalteu reagent method also. They established phenols to be the major antioxidant component found in the methanolic extracts from the mycelia of G. frondosa, as is the case here (Table 3). Overall, the extraction processes in the form of hot water and/or methanol positively influenced the concentration of antioxidant compounds and in doing so influenced antioxidant activity of G. frondosa, L. edodes, OYRM1, M. purpureus, P. 1833, P. 32783, P. eryngii, P. citrinopileatus, $P$. salmoneo-stramineus and $T$. versicolor.

\subsection{Relationship between antioxidant components and antioxidant properties}

A strong correlation between the total phenol content and $\mathrm{ABTS}^{+}$radical scavenging activity was observed for all the species tested, demonstrating that these compounds are responsible for the majority of the antioxidant capacities. As can be appreciated from Table 2, the total phenolic content extracted by the crude, hot water and methanol extraction processes, positively contributed to the $\mathrm{ABTS}^{+}$scavenging ability and reducing power potential for the majority of species. The total phenolic content of the crude extracts of $G$. frondosa, L. edodes, M. purpureus, OYRM1, P. 1833, T. versicolor, as well as, hot water extracts of G. frondosa, L. edodes, M. purpureus, P. 1833, P. 32783, P. eryngii, T. versicolor and methanol extracts of $G$. frondosa, L. edodes, M. purpureus, $P$. eryngii and $T$. versicolor showed significant correlation $(p \leqslant 0.05)$ to reducing power (Table 2 ). Apart from $L$. edodes, the phenolic content of each crude extract did not contribute to the chelating ability of fungi. However, the phenolic content of the hot water extract from G. frondosa, M. purpureus, P. citrinopileatus, P. salmoneo-stramineus and the methanol extract from $P .32783$, P. citrinopileatus and $P$. salmoneo-stramineus showed significant correlation $(p \leqslant 0.05)$ to chelating ability. In general, observations made from Table 2 emphasise that antioxidant activity of various extracts may be due to the reduction of hydroperoxide, inactivation of free radicals, complexation with metal ions or a combination thereof (Lee, Yen, \& Mau, 2007b).

It was observed that the overall total condensed tannin content of the crude, hot water and methanol extract of most species positively contributed to the reducing power activity, particularly following hot water extraction; by which a significant correlation was revealed between content and the reducing power $(p \leqslant 0.05)$ (Table 2). This is believed to be due to the water soluble nature of tannins and the efficiency of this extraction process in isolating them from the fungal cell. The tannin content extracted from the crude extract of each species did not contribute to the chelating ability of fungi. By using the microwave assisted hot water extraction process, the tannin content of $G$. frondosa and P. salmoneo-stramineus significantly correlated $(p \leqslant 0.05)$ to chelating ability and when extracted using methanol, $P$. 1833, P. salmoneo-stramineus and $T$. versicolor correlated to chelating ability also. These observations reveal that different compounds are extracted following different extraction procedures and these compounds have different affinities for different oxidative processes, most likely due to their polarity. It is appreciable from the data that the chelating ability of fungi may also be due to a different type of water soluble compound, for example, polysaccharides from fungi have recently been reported to have antioxidative capabilities (Zeng et al., 2010). The production of darker red pigmentation of $M$. purpureus with increasing concentration was concurrent with an increase of antioxidant potential. This observation is believed to be due to secondary metabolite production of this fungus in the form of phenolic compounds and pigment production derived from polyketides. 
Table 3

Overview of antioxidant constituents present in extracts from mycelium.

\begin{tabular}{|c|c|c|c|c|}
\hline Fungi & Extract & $\begin{array}{l}\text { Total phenol } \\
\text { mg GAE g }^{-1}\end{array}$ & $\begin{array}{l}\text { Total flavonoid } \\
\text { mg QE g }^{-1}\end{array}$ & $\begin{array}{l}\text { Total tannin } \\
\mathrm{mg} \mathrm{CE} \mathrm{g}^{-1}\end{array}$ \\
\hline Grifola frondosa & $\begin{array}{l}\text { Crude } \\
\text { Hot water } \\
\text { Methanol }\end{array}$ & $\begin{array}{l}2.31 \pm 0.50^{\mathrm{b}} \\
9.33 \pm 0.26^{\mathrm{a} *} \\
8.13 \pm 1.99^{\mathrm{a} *}\end{array}$ & $\begin{array}{l}0.16 \pm 0.01^{\mathrm{a}} \\
0.38 \pm 0.02^{\mathrm{a} *} \\
0.37 \pm 0.03^{\mathrm{b} *}\end{array}$ & $\begin{array}{l}1.97 \pm 0.17^{\mathrm{c}} \\
4.80 \pm 0.25^{\mathrm{a} *} \\
2.61 \pm 0.00^{\mathrm{b} *}\end{array}$ \\
\hline Lentinula edodes & $\begin{array}{l}\text { Crude } \\
\text { Hot water } \\
\text { Methanol }\end{array}$ & $\begin{array}{l}0.93 \pm 0.37^{\mathrm{c}} \\
9.09 \pm 0.16^{\mathrm{a} *} \\
5.73 \pm 0.04^{\mathrm{b} *}\end{array}$ & $\begin{array}{l}0.05 \pm 0.06^{\mathrm{b}} \\
0.33 \pm 0.04^{\mathrm{a} *} \\
0.27 \pm 0.05^{\mathrm{a} *}\end{array}$ & $\begin{array}{l}1.77 \pm 0.14^{\mathrm{c}} \\
5.11 \pm 0.29^{\mathrm{a} *} \\
2.40 \pm 0.00^{\mathrm{b} *}\end{array}$ \\
\hline Monascus purpureus & $\begin{array}{l}\text { Crude } \\
\text { Hot water } \\
\text { Methanol }\end{array}$ & $\begin{array}{l}1.98 \pm 0.49^{\mathrm{b}} \\
1.19 \pm 0.03^{\mathrm{b} *} \\
3.02 \pm 0.01^{\mathrm{a} *}\end{array}$ & $\begin{array}{l}0.22 \pm 0.02^{\mathrm{c}} \\
1.43 \pm 0.24^{\mathrm{a} *} \\
0.64 \pm 0.02^{\mathrm{b} *}\end{array}$ & $\begin{aligned} 2.28 & \pm 0.03^{\mathrm{b}} \\
10.52 & \pm 1.08^{\mathrm{a} *} \\
3.23 & \pm 0.14^{\mathrm{b}}\end{aligned}$ \\
\hline OYRM1 & $\begin{array}{l}\text { Crude } \\
\text { Hot water } \\
\text { Methanol }\end{array}$ & $\begin{array}{l}3.40 \pm 0.57^{\mathrm{b}} \\
5.60 \pm 1.84^{\mathrm{ab}} \\
7.45 \pm 0.62^{\mathrm{a}} *\end{array}$ & $\begin{array}{l}0.06 \pm 0.00^{\mathrm{b}} \\
2.17 \pm 0.72^{\mathrm{a} *} \\
0.85 \pm 0.03^{\mathrm{b}}\end{array}$ & $\begin{array}{l}2.39 \pm 0.43^{\mathrm{c}} \\
8.80 \pm 0.17^{\mathrm{a} *} \\
3.19 \pm 0.14^{\mathrm{b} *}\end{array}$ \\
\hline Pleurotus ostreatus 1833 & $\begin{array}{l}\text { Crude } \\
\text { Hot water } \\
\text { Methanol }\end{array}$ & $\begin{array}{l}4.82 \pm 0.86^{\mathrm{a}} \\
0.44 \pm 0.10^{\mathrm{b} *} \\
4.02 \pm 0.50^{\mathrm{a}}\end{array}$ & $\begin{array}{l}0.05 \pm 0.00^{\mathrm{c}} \\
2.83 \pm 0.18^{\mathrm{a} *} \\
0.84 \pm 0.03^{\mathrm{b} *}\end{array}$ & $\begin{aligned} 2.14 & \pm 0.13^{\mathrm{c}} \\
10.75 & \pm 0.61^{\mathrm{a} *} \\
6.90 & \pm 0.53^{\mathrm{b} *}\end{aligned}$ \\
\hline Pleurotus ostreatus 32783 & $\begin{array}{l}\text { Crude } \\
\text { Hot water } \\
\text { Methanol }\end{array}$ & $\begin{array}{l}3.66 \pm 0.43^{\mathrm{b}} \\
5.01 \pm 1.24^{\mathrm{b}} \\
9.29 \pm 0.45^{\mathrm{a} *}\end{array}$ & $\begin{array}{l}0.07 \pm 0.00^{\mathrm{c}} \\
1.08 \pm 0.13^{\mathrm{a} *} \\
0.74 \pm 0.02^{\mathrm{b} *}\end{array}$ & $\begin{array}{l}5.53 \pm 0.38^{\mathrm{a}} \\
6.01 \pm 0.20^{\mathrm{a}} \\
5.19 \pm 1.75^{\mathrm{a}}\end{array}$ \\
\hline Pleurotus citrinopileatus & $\begin{array}{l}\text { Crude } \\
\text { Hot water } \\
\text { Methanol }\end{array}$ & $\begin{array}{l}4.26 \pm 0.99^{\mathrm{b}} \\
2.55 \pm 0.25^{\mathrm{b}} \\
8.54 \pm 1.33^{\mathrm{a} *}\end{array}$ & $\begin{array}{l}0.07 \pm 0.01^{\mathrm{c}} \\
2.40 \pm 0.12^{\mathrm{a} *} \\
0.50 \pm 0.02^{\mathrm{b} *}\end{array}$ & $\begin{aligned} 8.86 & \pm 0.14^{\mathrm{c}} \\
18.83 & \pm 0.32^{\mathrm{a} *} \\
11.53 & \pm 1.38^{\mathrm{b} *}\end{aligned}$ \\
\hline Pleurotus eryngii & $\begin{array}{l}\text { Crude } \\
\text { Hot water } \\
\text { Methanol }\end{array}$ & $\begin{array}{l}4.12 \pm 1.94^{\mathrm{ab}} \\
1.63 \pm 0.24^{\mathrm{b}} \\
5.69 \pm 1.24^{\mathrm{a}}\end{array}$ & $\begin{array}{l}0.37 \pm 0.02^{\mathrm{c}} \\
1.69 \pm 0.08^{\mathrm{a} *} \\
0.73 \pm 0.03^{\mathrm{b} *}\end{array}$ & $\begin{array}{l}2.78 \pm 0.00^{\mathrm{b}} \\
6.86 \pm 1.10^{\mathrm{a} *} \\
3.19 \pm 0.29^{\mathrm{b}}\end{array}$ \\
\hline Pleurotus salmoneo-stramineus & $\begin{array}{l}\text { Crude } \\
\text { Hot water } \\
\text { Methanol }\end{array}$ & $\begin{array}{l}4.14 \pm 0.27^{\mathrm{a}} \\
4.12 \pm 1.95^{\mathrm{a}} \\
5.72 \pm 0.68^{\mathrm{a}}\end{array}$ & $\begin{array}{l}0.07 \pm 0.00^{\mathrm{c}} \\
3.90 \pm 0.23^{\mathrm{a} *} \\
1.22 \pm 0.03^{\mathrm{b} *}\end{array}$ & $\begin{array}{r}4.03 \pm 1.41^{\mathrm{b}} \\
15.94 \pm 0.38^{\mathrm{a} *} \\
5.28 \pm 0.52^{\mathrm{b}}\end{array}$ \\
\hline Trametes versicolor & $\begin{array}{l}\text { Crude } \\
\text { Hot water } \\
\text { Methanol }\end{array}$ & $\begin{array}{l}1.90 \pm 0.15^{\mathrm{b}} \\
7.34 \pm 2.31^{\mathrm{a} *} \\
7.70 \pm 1.47^{\mathrm{a} *}\end{array}$ & $\begin{array}{l}0.02 \pm 0.00^{\mathrm{b}} \\
0.87 \pm 0.06^{\mathrm{a} *} \\
0.84 \pm 0.03^{\mathrm{a} *}\end{array}$ & $\begin{array}{l}2.44 \pm 0.29^{\mathrm{b}} \\
6.00 \pm 0.54^{\mathrm{a} *} \\
3.32 \pm 0.29^{\mathrm{b}}\end{array}$ \\
\hline
\end{tabular}

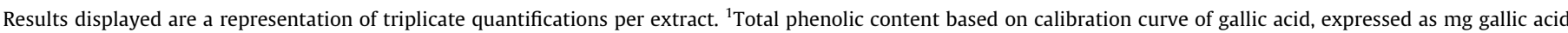

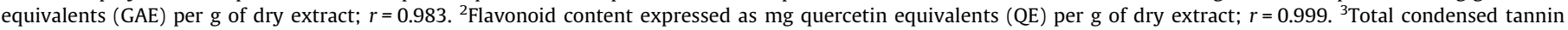

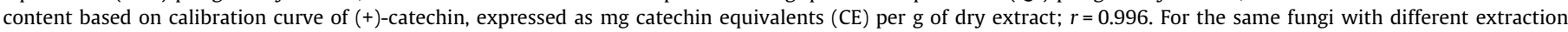

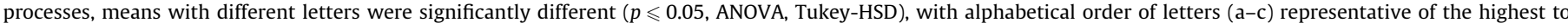

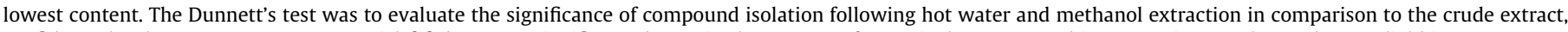

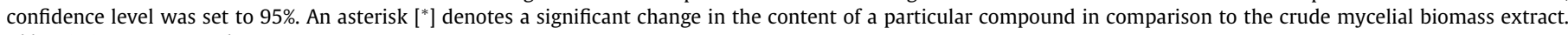
Abbreviations: OYRM1, Pleurotus ostreatus.

Dimerumic acid was previously established as having inhibiting NADPH- and iron (II)-dependant lipid peroxidation of rat liver microsomes (Aniya et al., 2000). Due to the considerable contribution of the water soluble phenolic compounds, it is possible that the poor correlation of both crude and hot water extracts be attributed to the fast reduction in ions. It was observed that at low concentrations of extract there was a high rate of chelation (\%) which increased with increasing concentration. In addition, at low concentrations of mycelial extract, the majority of metal ions were chelated in comparison to the methanol extracts.

The antioxidant activities of polyphenols, as well as their metal chelating abilities were attributed to their redox properties, which allow them to act as reducing agents, hydrogen donators and singlet oxygen quenchers (Vaz et al., 2011). Other components which were not quantified in this instance are also believed to have contributed to the antioxidant activity of fungal extracts. However, phenolic, flavonoid and tannin compounds made a significant contribution to the antioxidant activity of each species. Variations in antioxidant activity between extracts may be attributed to aqueous extracts having high polyphenol content and the methanol extract having higher carotenoid and ascorbic acid content (Oke \& Aslim, 2011). Compounds associated with antioxidant activity include ascorbic acid, $\beta$-carotene and tocopherols $(\alpha, \beta$ and $\gamma$ ) (Ferreira et al., 2009); however, due to the heat sensitive characteristics of ascorbic acid, as well as the fat-soluble nature of tocopherols and $\beta$-carotene, it is unlikely these compounds were extracted into hot water extracts (Lee et al., 2007b). Altogether, many fungi contain different antioxidants, such as phenolic compounds, tocopherols, ascorbic acid and carotenoids, which could be specifically extracted for the purpose of being used as functional ingredients against diseases related to oxidative stress (Ferreira et al., 2009).

According to the data obtained, phenols, flavonoids and condensed tannin were found to be effective antioxidants in different in vitro assays including reducing power, $\mathrm{ABTS}^{+}$radical scavenging and metal chelating activities when compared to standard antioxidant compounds, such as BHT, Trolox, EDTA and $\alpha$-tocopherol. Based on the results obtained, the fungal extracts show great potential for minimising or preventing lipid oxidation in food products, retarding the formation of toxic oxidation products, maintaining nutritional quality and prolonging the shelf life of foods and pharmaceuticals.

\section{Conclusion}

In the present investigation, a number of antioxidant assay systems were assessed in an attempt to elucidate the presence of antioxidants produced in mycelial biomass using submerged liquid cultivation. It was determined that the various antioxidants 
produced in the mycelium were radical scavengers and primary chain-breaking antioxidants. This investigation demonstrated that depending on the process of extraction, different yields of antioxidant compounds were recovered. Additionally, methanolic extracts were typically more effective in antioxidant properties. It was concluded that the overall antioxidant capacity of these filamentous fungi was attributed mainly to their phenolic content. These species of fungi show promising activity for further application. The growth of G. frondosa, M. purpureus, Pleurotus spp., L. edodes and T. versicolor using submerged cultivation proved to be a suitable method for the production of natural antioxidants, which could potentially be used for supplementation purposes, development of nutraceuticals or to partially substitute synthetic antioxidants which are currently used, such as BHT.

\section{References}

Abdullah, N., Ismail, S. M., Aminudin, N., Shuib, A. S., \& Fye, L. B. (2012). Evaluation of selected culinary-medicinal mushrooms for antioxidant and ACE inhibitory activities. Evidence-Based Complementary and Alternative Medicine, 2012, 12.

Al-Azzawie, H. F., \& Alhamdani, M.-S. S. (2006). Hypoglycemic and antioxidant effect of oleuropein in alloxan-diabetic rabbits. Life Sciences, 78, 1371-1377.

Aniya, Y., Ohtani, I. I., Higa, T., Miyagi, C., Gibo, H., Shimabukuro, M., et al. (2000) Dimerumic acid as an antioxidant of the mold, Monascus anka. Free Radical Biology and Medicine, 28, 999-1004.

Apak, R., Guclu, K., Demirata, B., Ozyurek, M., Celik, S. E., Bektasoglu, B., et al. (2007). Comparative evaluation of various total antioxidant capacity assays applied to phenolic compounds with the CUPRAC assay. Molecules, 12, 1496-1547.

Apak, R., Güçlü, K., Özyürek, M., Bektas, B. O., \& Bener, M. (2008). Cupric ion reducing antioxidant capacity assay for food antioxidants: Vitamins, polyphenolics, and flavonoids in food extracts. Methods in Molecular Biology, 477, 163-193.

Arnao, M. B. (2000). Some methodological problems in the determination of antioxidant activity using chromogen radicals: A practical case. Trends in Food Science \& Technology, 11, 419-421.

Asatiani, M. D., Elisashvili, V., Songulashvili, G., Reznick, A. Z., \& Wasser, S. P. (2010). Higher Basidiomycetes mushrooms as a source of antioxidants. In M. Rai \& G. Kövics (Eds.), Progress in mycology (pp. 311-326). Netherlands: Springer.

Balasundram, N., Sundram, K., \& Samman, S. (2006). Phenolic compounds in plants and agri-industrial by-products: Antioxidant activity, occurrence, and potential uses. Food Chemistry, 99, 191-203.

Blackwell, M. (2011). The fungi: 1, 2, 3,. . 5.1 million species? American Journal of Botany, 98, 426-438.

Bravo, L. (1998). Polyphenols: Chemistry, dietary sources, metabolism, and nutritional significance. Nutrition Reviews, 56, 317-333.

Chang, R. (1996). Functional properties of edible mushrooms. Nutrition Reviews, 54, S91-S93.

Chang, S. T., \& Buswell, J. A. (1996). Mushroom nutriceuticals. World Journal of Microbiology and Biotechnology, 12, 473-476.

Dinis, T. C. P., Madeira, V. M. C., \& Almeida, L. M. (1994). Action of phenolic derivatives (Acetaminophen, Salicylate, and 5-Aminosalicylate) as inhibitors of membrane lipid peroxidation and as peroxyl radical scavengers. Archives of Biochemistry and Biophysics, 315, 161-169.

Elisashvili, V. (2012). Submerged cultivation of medicinal mushrooms: Bioprocesses and products (Review). International Journal of Medicinal Mushrooms, 14, 211-239.

Ferreira, I. C. F. R., Baptista, P., Vilas-Boas, M., \& Barros, L. (2007). Free-radical scavenging capacity and reducing power of wild edible mushrooms from northeast Portugal: Individual cap and stipe activity. Food Chemistry, 100, 1511-1516.

Ferreira, I. C. F. R., Barros, L., \& Abreu, R. M. V. (2009). Antioxidants in wild mushrooms. Current Medical Chemistry, 16, 1543-1560.

Huang, D., Ou, B., \& Prior, R. L. (2005). The chemistry behind antioxidant capacity assays. Journal of Agricultural and Food Chemistry, 53, 1841-1856.
Jayakumar, T., Thomas, P. A., \& Geraldine, P. (2009). In-vitro antioxidant activities of an ethanolic extract of the oyster mushroom, Pleurotus ostreatus. Innovative Food Science and Emerging Technologies, 10, 228-234.

Lee, Y.-L., Huang, G.-W., Liang, Z.-C., \& Mau, J.-L. (2007a). Antioxidant properties of three extracts from Pleurotus citrinopileatus. LWT - Food Science and Technology, 40, 823-833.

Lee, Y.-L., Yen, M.-T., \& Mau, J.-L. (2007b). Antioxidant properties of various extracts from Hypsizigus marmoreus. Food Chemistry, 104, 1-9.

Lindequist, U., Niedermeyer, T. H. J., \& Julich, W.-D. (2005). The pharmacological potential of mushrooms. Evidence-Based Complementary and Alternative Medicine, 2, 285-299.

Liu, R. H. (2004). Potential synergy of phytochemicals in cancer prevention: Mechanism of action. Journal of Nutrition, 134, 3479S-3485S.

Mau, J.-L., Chang, C.-N., Huang, S.-J., \& Chen, C.-C. (2004). Antioxidant properties of methanolic extracts from Grifola frondosa, Morchella esculenta and Termitomyces albuminosus mycelia. Food Chemistry, 87, 111-118.

Miller, H. (1971). A simplified method for the evaluation of antioxidants. Journal of the American Oil Chemists' Society, 48, 91.

Miller, N. J., Riceevans, C., Davies, M. J., Gopinathan, V., \& Milner, A. (1993). A novel method for measuring antioxidant capacity and its application to monitoring the antioxidant status in premature neonates. Clinical Science, 84, 407-412.

Oke, F., \& Aslim, B. (2011). Protective effect of two edible mushrooms against oxidative cell damage and their phenolic composition. Food Chemistry, 128, 613-619.

Ong, E.S., Woo, S.O., Yong, Y.L. and Binte, A.S.N. (2003). Pressurized liquid extraction method and apparatus. Patent, U. S., US 20030096422A1, Available from: SciFinder Scholar [17/09/2014].

Oyaizu, M. (1986). Studies on products of browning reaction. antioxidative activities of products of browning reaction prepared from glucosamine. The Japanese Journal of Nutrition and Dietetics, 44, 307-315.

Prior, R. L., Wu, X., \& Schaich, K. (2005). Standardized methods for the determination of antioxidant capacity and phenolics in foods and dietary supplements. Journal of Agricultural and Food Chemistry, 53, 4290-4302.

Pulido, R., Bravo, L., \& Saura-Calixto, F. (2000). Antioxidant activity of dietary polyphenols as determined by a modified ferric reducing/antioxidant power assay. Journal of Agricultural and Food Chemistry, 48, 3396-3402.

Quettier-Deleu, C., Gressier, B., Vasseur, J., Dine, T., Brunet, C., Luyckx, M., et al. (2000). Phenolic compounds and antioxidant activities of buckwheat (Fagopyrum esculentum Moench) hulls and flour. Journal of Ethnopharmacology, $72,35-42$.

Rajauria, G., Jaiswal, A. K., Abu-Gannam, N., \& Gupta, S. (2013). Antimicrobial, antioxidant and free radical-scavenging capacity of brown seaweed Himanthalia elongata from western coast of Ireland. Journal of Food Biochemistry, 37, 322-335.

Singleton, V. L. (1985). Colorimetry of total phenolics with phosphomolybdicphosphotungstic acid reagents. Current Contents/Agriculture Biology $\mathcal{E}$ Environmental Sciences, 48, 18.

Shimada, K., Fujikawa, K., Yahara, K., \& Nakamura, T. (1992). Antioxidative properties of xanthan on the autoxidation of soybean oil in cyclodextrin emulsion. Journal of Agricultural and Food Chemistry, 40, 945-948.

Taylor, M. J., \& Richardson, T. (1980). Antioxidant activity of cysteine and protein sulfhydryls in a linoleate emulsion oxidized by hemoglobin. Journal of Food Science, 45, 1223-1227.

Vamanu, E. (2012). Biological activities of the polysaccharides produced in submerged culture of two edible Pleurotus ostreatus mushrooms. Journal of Biomedicine and Biotechnology, 565974-565982.

Vaz, J. A., Barros, L., Martins, A., Santos-Buelga, C., Vasconcelos, M. H., \& Ferreira, I. C. F. R. (2011). Chemical composition of wild edible mushrooms and antioxidant properties of their water soluble polysaccharidic and ethanolic fractions. Food Chemistry, 126, 610-616.

Wasser, S. P. (2002). Medicinal mushrooms as a source of antitumor and immunomodulating polysaccharides. Applied Microbiology and Biotechnology, 60, 258-274.

Yim, H. S., Fook, Y. C., See, K. H., \& Chun, W. H. (2009). Phenolic profiles of selected edible wild mushrooms as affected by extraction solvent, time and temperature. Asian Journal of Food and Agro-Industry, 2, 9.

Zeng, R.-Y., He, R.-T., Wei, W., Xu, X.-Y., Zhang, X.-P., Luo, X., et al. (2010). Antioxidant properties of polysaccharides from Ganoderma sinense by different cultivations. Food Science and Technology Research, 16, 143-148. 